\title{
Estudo das Células Neuro2a Sobre os Biomateriais PCL e PLLA
}

\author{
Luiz Gabriel Maturana, Amauri Pierucci \\ Departamento de Ciências Básicas, Universidade Federal dos Vales do Jequitinhonha e Mucuri- UFVJM \\ Gustavo Ferreira Simões, Alexandre Leite Rodrigues de Oliveira \\ Laboratório de Regeneração Nervosa, Departamento de Anatomia Humana, Instituto de Biologia - IB, \\ Universidade Estadual de Campinas - UNICAMP \\ Laboratório Eliana Aparecida de Rezende Duek \\ Eliana Aparecida de Rezende Duek
Faculdade de Engenharia Mecânica, \\ Universidade Estadual de Campinas - UNICAMP
}

\begin{abstract}
Resumo: Os biomateriais poli L-ácido lático (PLLA) e o poli caprolactona (PCL) são os polímeros mais estudadas na área dos materiais bioreabsorvíveis. Dentre as suas principais características que contribuem para a interação celular, temos a especificidade química da superfície, elétrica, hidrofobicidade e topografia. Ainda, observa-se o tempo de degradação, porosidade, biocompatibilidade com o tecido biológico, bem como, a confecção com as mais variadas formas e dimensões. Já a prática da cultura celular, tem como objetivo estudar a adesão, migração, diferenciação e a proliferação celular utilizando-se um determinado material ou substância. Contudo, poucos trabalhos utilizando os biomateriais ora supracitados e a aplicação em células neuro2A foram realizados. Sabe-se que este tipo celular é derivado de células embrionárias da crista neural, as quais originam em neurônios simpáticos e apresentam como característica a imortalidade, portanto, são excelentes modelos em ensaios in vitro. Nesse sentido, o presente estudo avalia a adesão e a proliferação desta linhagem celular sobre os biopolímeros poli caprolactona (PCL) e poli L-ácido lático (PLLA).
\end{abstract}

Palavras-chave: Biomateriais, PLLA, PLC, neuroblastoma, cultura.

\section{Study of Neuro2a Cells on the Biomaterials Poly L-lactic Acid and Poly Caprolactone}

\begin{abstract}
Biomaterials poly L-lactic acid (PLLA) and poly caprolactone (PCL) are the most studied in the area of bioresorbable materials. Among the main features that contribute to cell interaction, we have the specific surface chemistry, electrical, hydrophobicity and topography. Also, is observed the degradation time, porosity, biocompatibility with biological tissue, as well as the preparation of the most varied shapes and sizes. The practice of cell culture, aims to study the adhesion, migration, differentiation and cell proliferation using a given material or substance. However, few studies were performed using these biomaterials and the application of neuro2A cells. It is known that this cell type is derived from the embryonic neural crest cells, which originate in sympathetic neurons and have the characteristic of immortality, therefore, are excellent models in vitro assays. Accordingly, the present study evaluates the adhesion and proliferation of this cell line on the biopolymers poly caprolactone (PCL) and poly L-lactic acid (PLLA).
\end{abstract}

Keywords: Biomaterials, PLLA, PLC, neuroblastoma, culture.

\section{Introdução}

Com o advento da bioengenharia intensificaram os estudos sobre a aplicação e ação dos biomateriais em diferentes tipos celulares. Sabe-se que a adesão, migração, diferenciação e a proliferação celular sobre determinado substrato depende em parte das propriedades intrínsecas de cada tipo celular, bem como, o tipo de material utilizado ${ }^{[1-4]}$. Dentre os produtos celulares, pode-se ressaltar a síntese de moléculas de adesão celular, como laminina, fibronectina e colágeno, importantes para o cultivo e o crescimento celular $^{[5,6]}$. Além disso, alguns experimentos in vitro demonstraram que a utilização de fatores de crescimento e outras substâncias como o interferon e acetato de glatiramer provocam a proliferação celular ${ }^{[7,8]}$. Por outro lado, as características intrínsecas dos biomateriais, como a especificidade química da superfície, elétrica, hidrofobicidade e topografia, podem influenciar na adesão e crescimento celular ${ }^{[1,3,4,9,10]}$.

Ainda, observa-se que dentre os biomateriais utilizados para o cultivo celular, os poli $\alpha$-hidróxi ácidos, vêm se tornando uma das famílias de polímeros mais promissoras e estudadas na área dos materiais bioreabsorvíveis, destacando-se o poli ácido glicólico (PGA) e o poli caprolactona (PCL), por atuarem positivamente em vários ensaios in vivo e in vitro ${ }^{[2,9,11-16]}$. A grande vantagem desses polímeros está na sua forma de degradação, que ocorre por hidrólise de suas ligações ésteres, sendo os produtos resultantes da degradação completamente absorvidos pelo organismo ${ }^{[17]}$. Entre outras vantagens, observa-se o tempo de degradação, porosidade de sua superfície, resistência

Autor para correspondência: Amauri Pierucci, Departamento de Ciências Básicas, Universidade Federal dos Vales do Jequitinhonha e Mucuri - UFVJM, Rua da Glória, 187, Centro, CEP 39100-000, Diamantina, MG, Brasil, e-mail: pierucci@ufvjm.edu.br 
mecânica e a biocompatibilidade com o tecido biológico, bem como, a confecção com as mais variadas formas e dimensões ${ }^{[2,9,11-13]}$.

Várias pesquisas utilizando-se os biomateriais no reparo do sistema nervoso periférico, evidenciaram excelentes resultados no processo regenerativo e demonstraram que os biomaterias apresentam a característica positivas quanto a biocompatibilidade ${ }^{[15,16,18-20]}$.

Outros ensaios envolvendo os polímeros PCL, PLGA e o copolímero poli ${ }_{\mathrm{L}}{ }^{-\mathrm{co}-}{ }_{\mathrm{D}},{ }_{\mathrm{L}}$-ácido láctico (PLDLA), conferiram o caráter de serem biocompatíveis e mantiveram a viabilidade celular in vitro ${ }^{[11-13,15,21]}$.

Já, quando aplicados os biomateriais no sistema nervoso central, estes se mostraram viáveis e provocaram a diferenciação celular e maturação neuronal ${ }^{[22,23]}$. Segundo Teixeira et al. ${ }^{[22]}$, quando o substrato apresenta as mesmas características do tecido cerebral, ou seja, a propriedade mecânica da elasticidade, este tem a capacidade de promover a maturação e a diferenciação de células indiferenciadas em neurônios e também realizar a sustentação e proliferação dos astrócitos.

Ainda, quando cultivadas células indiferenciadas sobre matriz de Chitosan acrescidos da proteína verde fluorescente (GFP) e aplicadas no local da lesão medular, notou-se que as mesmas diferenciaram-se em astrócitos, oligodentrócitos e neurônios, portanto, este material atua positivamente na regeneração do tecido ${ }^{[23]}$.

De acordo com as observações realizadas por Wong et al. ${ }^{[24]}$, o uso do PLGA e PCL no sistema nervoso central permitiu o crescimento neuronal e redução das lesões secundárias, como a redução da atividade astrocitária e prevenção ao aumento do tecido cicatricial. Ainda, os autores evidenciaram que o PCL seria uma alternativa ao PLGA, pois este apresenta menor tempo de degradação, torna o $\mathrm{pH}$ menor do microambiente nervoso e induz uma baixa resposta inflamatória.

Contudo, poucos trabalhos utilizando-se os biomateriais e a aplicação em células neuro2A foram realizados. Sabe-se que este tipo celular é derivado de células embrionárias da crista neural, as quais originam em neurônios simpáticos e apresentam como característica principal a imortalidade ${ }^{[25,26]}$ e, tornam-se excelentes modelos experimentas em pesquisas. O trabalho mais recente envolvendo este tipo celular e um copolímero foi realizado por Rao et al. ${ }^{[27]}$, ao observar que o nanomaterial sintetizado a partir do poli-Dlisina e o derivado de Norborneno serviam como substrato para o crescimento neuronal, orientação e diferenciação das mesmas. Já a adição de fatores em meio de cultivo celular, como a proteína beta, acido disialico e fosfocolina citidilitransferease beta 2, arginina N-metiltransferase, glangliosídeo GM1, também induziram a diferenciação neuronal destas ${ }^{[28]}$.

Entretanto, estudos mais recentes abordaram a regulação da transcrição do fator neurotrófico mesencefálico derivado astrócitos nas células neuro2 $\mathrm{A}^{[29]}$. Outros, entretanto, avaliaram os efeitos de oxidantes na adenosina monofosfato quinase ativada (AMPK) sobre o metabolismo energético destas células ${ }^{[30]}$. Desta forma, tendo-se em vista a pouca quantidade de trabalhos utilizando-se as células neuro2a e o uso de biomateriais, o propósito deste estudo será avaliar a capacidade dos biopolímeros poli caprolactona (PCL) e poli Lácido lático (PLLA) na adesão e proliferação das mesmas in vitro.

\section{Experimental}

\section{Confecção de membranas de PCL e PLLA}

Os biopolímeros, poli-caprolactona (PCL) e poli L-ácido lático (PLLA) foram adquiridos junto ao DEMA. As membranas de PCL e PLLA foram confeccionadas a partir da técnica do solvente ${ }^{[31]}$. Para isto, as amostras foram colocadas separadamente em $33 \mathrm{ml}$ de solvente (dicloroetano) (Merck, Darmstadt, Alemanha), de modo que as concentrações finais fossem $5 \%$ e $2,5 \%$ respectivamente (peso/volume). A seguir, as soluções permanecerão em temperatura ambiente por 12 horas para completa homogeneização. Em seguida, cada uma foi colocada em uma placa contida no interior de uma cuba de vidro com o meio saturado de solvente. Esperar-se-á por 12 horas para evaporação completa do solvente. Por fim, as membranas foram retiradas da cuba, sendo estas colocadas em uma câmara de vácuo por 5 minutos, de forma que eventuais resíduos do solvente não permanecessem nas mesmas. Posteriormente, as membranas foram colocadas na câmara de vácuo e cortadas de acordo com o tamanho dos poços da placa de cultura ( 24 poços), aproximadamente com $2,0 \mathrm{~mm}$ de diâmetro. Antecedendo a preparação da cultura de células neuro2a, as membranas foram desinfetadas em álcool 70\%, em seguida, lavadas com meio de cultura e colocadas nos respectivos poços, recebendo posteriormente as células de neuroblastoma.

\section{Cultura de células Neuro2a}

As células de neuroblastoma humana, linhagem neuro2a, foram obtidas da coleção de linhagens celulares do Laboratório de Regeneração Nervosa da UNICAMP. Inicialmente, as células neuro2A estavam armazenadas em criotubo no interior do botijão criogênico contendo nitrogênio líquido, sob uma temperatura de $-273^{\circ} \mathrm{C}$. Em seguida as células foram retiradas do botijão e colocadas em água do banho maria a $36^{\circ} \mathrm{C}$. Após, foram colocadas em tubos Falcon com 4ml de meio DMEM, centrifugadas por 5 minutos e ressuspendidas em meio de cultura de cultura e armazenadas em garrafa de cultura celular de $75 \mathrm{~cm}^{2}$. Passados 03 dias de cultivo no interior do frasco de cultura contendo meio modificado Eagle (DMEM) com 10\% de soro fetal bovino e $1 \%$ de penicilina-estreptomicina, para crescimento e confluência celular, estas foram lançadas na placa de cultura de 24 poços (100mm) contendo poly l-lisina (Sigma) (grupo controle) e sobre as membranas de PCL e PLLA no interior do poço. Em seguida, foram armazenadas em incubadora $\mathrm{CO}_{2}$ à temperatura de $37^{\circ} \mathrm{C}$ e atmosfera de $5 \%$, e cultivadas durante o período de 07 dias.

Todo o experimento será feito em triplicata e examinada diariamente. Ainda, serão capturados campos da cultura com o auxílio do Microscópio invertido (Nikon eclipse TS100) conectado a câmera Nikon (DMX1200F) para acompanhar o crescimento celular. Já o número de células foi quantificado com o software Image Tool (versão 3.0, 
UTHSCSA, USA) através da contagem dos núcleos celulares feitas pela marcação com PCNA e DAPI.

\section{Imunocitoquímica e quantificação das células Neuro2a}

Após 07 dias de cultura, as amostras foram fixadas em paraformoldeído $4 \%$ por 10 minutos e lavadas 2 vezes em tampão fosfato (PB) $0,1 \mathrm{M}, \mathrm{pH} 7,4$ por 5 minutos. Para evitar marcações inespecíficas, as culturas foram incubadas por 45 minutos em uma solução contendo albumina bovina (Sigma) $1 \%$ e triton X $(0,25 \%)$ em PB. Em seguida, as preparações foram incubadas com o anticorpo PCNA (antígeno nuclear de proliferação celular) por 2 horas em temperatura ambiente. As amostras serão lavadas 2 vezes em $\mathrm{PB} 0,1 \mathrm{M}, \mathrm{pH} 7,4$ por 5 minutos, e incubadas com anticorpo secundário fluorescente $\mathrm{CY}-3$, (diluição 1:500) por 45 minutos em temperatura ambiente. Após a imunomarcação, ocorrereu a citoquímica das amostras com DAPI por 10 minutos. Posteriormente, o material sofreu novamente 2 lavagens em $\mathrm{PB} 0,1 \mathrm{M}, \mathrm{pH} 7,4$ por 5 minutos.

Em seguidas, as membranas foram colocadas e lâminas e montadas em glicerol (1:3 de PB). Foram capturados 3 campos representativos de cada membrana, com o auxílio do Microscópio invertido (Nikon eclipse TS100) (Nikon eclipse TS100) equipado com sistema de epifluorescência e conectado a câmera Nikon (DMX1200F) para captura de imagens.

Para a quantificação do número de células de cada campo, utilizou-se o software Image Tool (versão 3.0, UTHSCSA, USA), sendo que a contagem foi feita pelos núcleos celulares marcados com PCNA (Antígeno Nuclear de Proliferação Celular) e DAPI (4',6-diamidino-2fenilindol).

\section{Resultados e Discussão}

A confecção das membranas de PCL e PLLA foram feitas a partir da técnica do solvente ${ }^{[31]}$, de acordo com a metodologia apresentada na confecção das membranas. Devido a sua leveza, foram colocadas arruelas de titânio sobre a biomembranas a fim de evitar que ocorresse a flutuação destas durante e após a colocação das células do neuroblastoma e o meio de cultura. Inicialmente, adicionou-se $100 \mu \mathrm{L}$ de meio DMEM sobre o biomaterial. Passados 45 minutos para adesão celular no substrato, completou-se com $100 \mu \mathrm{L}$ do mesmo meio. Devido à opacidade da membrana de PCL, e a pouca transparência da membrana de PLLA, utilizou-se como controle deste experimento o poço da placa de cultura sem o biomaterial e, isto permitiu-nos a orientação a respeito da confluência da cultura celular. Além disso, percebe-se a maior regularidade da superfície do polímero PLLA quando comparado ao PCL (Figura 1).

Já, para o cálculo do número de células lançadas em cada poço da placa de cultura, utilizou-se a seguinte fórmula: Número de quadrantes contados (normalmente 10 quadrantes da câmara de Neubauer) $\times 10.000$ (fator de correção da câmara) $=$ Número de células por mililitro (cel/ml). O número de células lançadas foi estimado em $10 \times 10^{3}$ células. Durante a experimentação, observou-se, em contraste de fase e com a dupla marcação, que essas células tinham como características a morfologia circular de seu citoplasma, típicas de células de neuro2A (Figura 2a, Figura 2d, Figura 2e, Figura 2f).

Após 7 dias de cultivo celular sobre as biomembranas de PCL e PLLA e no grupo controle, realizou-se a dupla marcação, utilizando-se o anticorpo para o PCNA e o corante DAPI, os quais revelaram uma intensa marcação na cultura de neuro2A (Figura 2d, Figura 2e, Figura 2f). Nesse sentido, observou-se que o número de células marcadas no grupo controle foi superior ao número de células sobre ambos biomateriais. Contudo, nota-se que o contingente celular sobre a membrana de PLLA (Figura 2f) foi superior do que na membrana de PCL (Figura 2e, Gráfico 1). Isso mostra que os biomateriais influenciam diferentemente na adesão celular.

A partir dos resultados numéricos da contagem das células de neuroblastoma, foram calculados a média e desvio-padrão. Estes parâmetros foram analisados
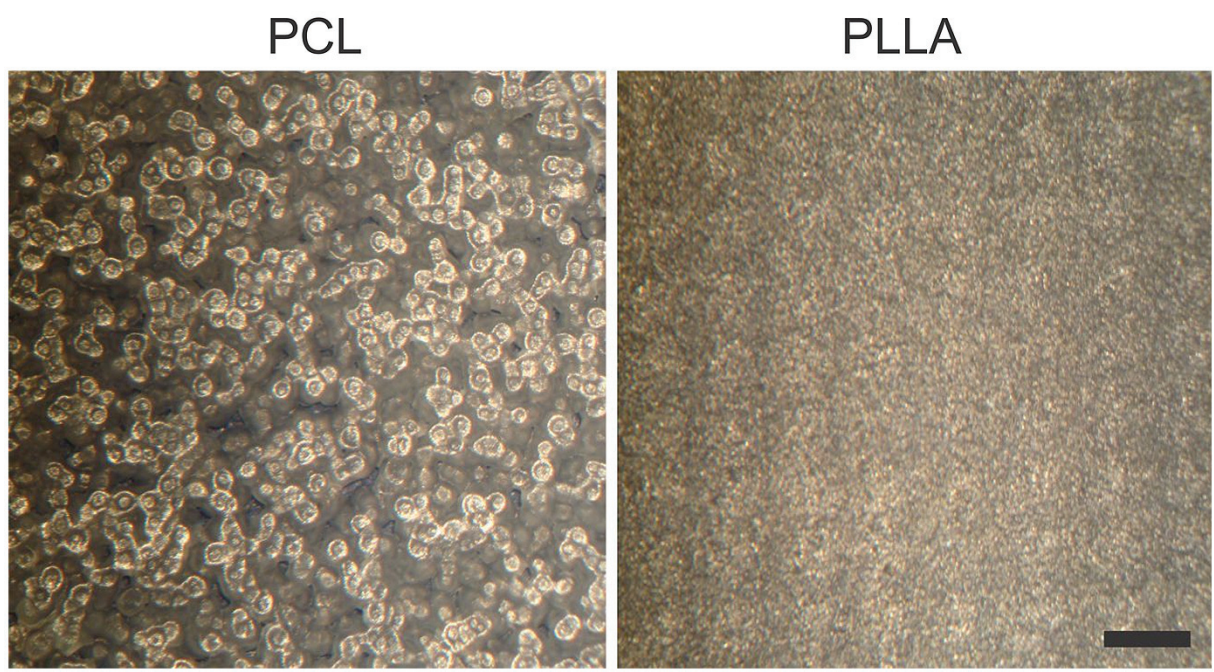

Figura 1. Fotomicrografia das membranas de poli caprolactona (PCL) e poli ${ }_{\mathrm{L}}$-ácido lático (PLLA), confeccionadas pelo método solvente. Observe que a membrana de PLLA apresenta uma superfície mais regular quando comparado com a membrana de PCL; Escala = $1 \mathrm{~cm}$. 

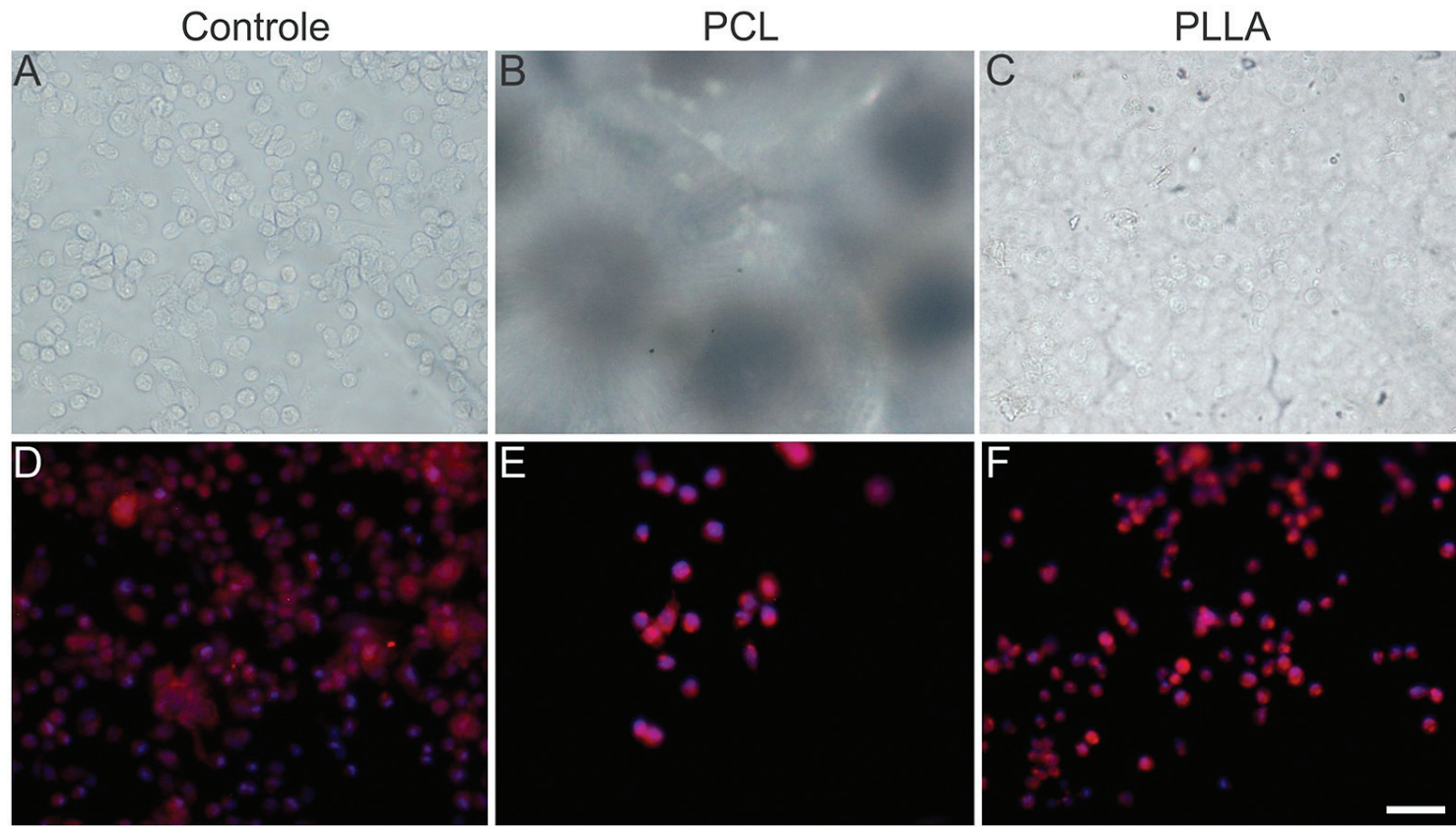

Figura 2. Contraste de fase da cultura de células neuro2A (A, B e C) e dupla marcação feita através da Imunocitoquímica (anticorpo PCNA) e Citoquímica (corante DAPI) (D, E, F). Observe o maior contingente celular no grupo controle. Com relação aos polímeros, o PLLA apresentou uma melhor adesão celular em relação ao PCL. Ainda a membrana de PLLA por ser mais regular em sua superfície, facilitou a visualização das células neuro2A em relação ao PCL; Escala $=10 \mu \mathrm{m}$.

DAPI

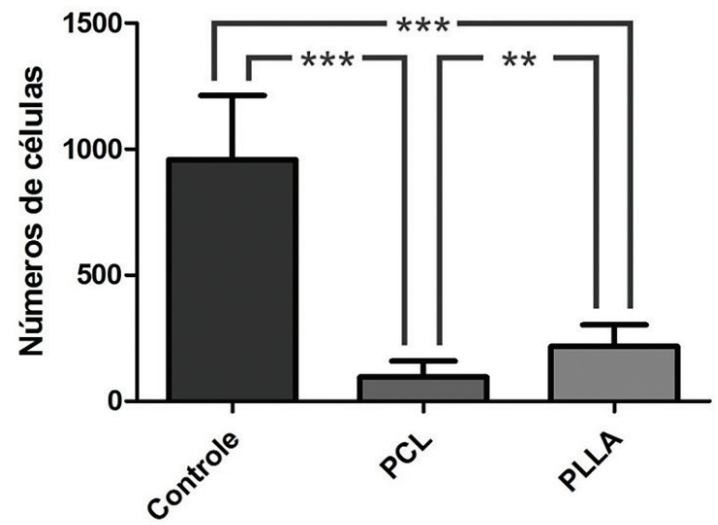

Grupos
PCNA

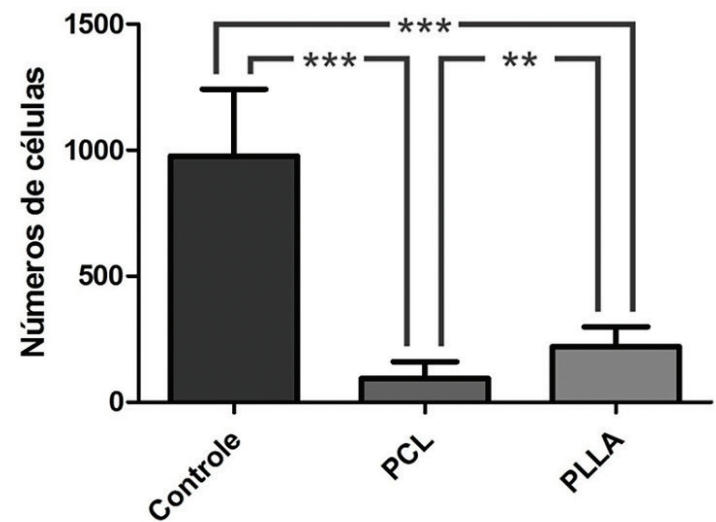

Grupos

Gráfico 1. Contagem de células neuro2A após 7 dias de cultura, no grupo controle e sobre os biomateriais PCL e PLLA. Observe que o número de células no grupo controle foi estatisticamente superior os grupos PCL e PLLA. Já o número de células sobre o biomaterial PLLA foi significantemente superior quando comparado ao polímero $\mathrm{PCL}(* * \mathrm{P}<0,01$ e $* * * \mathrm{P}<0,001$, Teste $t$ de Student).

fazendo-se uso do teste " $t$ " de Student, assumindo-se um nível de significância igual a $* \mathrm{P}<0,05 ; * * \mathrm{P}<0,01$; $* * * \mathrm{P}<0,001$.

O grupo controle apresentou um número médio de $1007 \pm 263,63$ células presenciadas em contraste de fase (Figura 2a), 976 $\pm 265,10$ marcadas com PCNA quando observadas em epifluorecência com filtro para fluoresceina e $958 \pm 254,75$ coradas com o DAPI quando observadas com filtro para rodamina (Gráfico 1).

Já quando foi realizado a contagem celular sobre a membrana de PCL, notou-se a presença média de
$55,88 \pm 33,58$ células para a marcação para PCNA e $51,11 \pm 28,55$ células de neuro2A para o DAPI. Deve-se ressaltar que devido a opacidade e irregularidade da membrana de PCL, não foi possível realizar a contagem sob o contraste de fase (Gráfico 1). Em contrapartida, o número médio de células presentes sobre o biomaterial PLLA foi $129 \pm 40,06$ para a imuno feita com PCNA e 130,33 $\pm 54,29$ para a citoquímica para o DAPI.

Após a contagem das células marcadas e coradas, realizou-se a análise estatística e, notou-se que o número de células presentes no grupo controle foi superior aos 
grupos PCL E PLLA. Ainda, o grupo PLLA apresentou maior significância quando comparado ao PCL (Gráfico 1).

Sabe-se que a utilização de biomateriais vêm sendo utilizada intensamente nestes últimos anos na cultura celular para fins de estudo na adesão, crescimento celular, citoxicidade, citocompatibilidade e diferenciação celular $^{[1,3,4,10,32]}$. Nesse intuito, vários biomateriais foram testados ao longo dos anos, entre eles, o poli ácido lático (PLLA), poli caprolactona (PCL), chitosana e poliuretano ${ }^{[9,16,31,33]}$. O estudo dos biomateriais ora supracitados, entre outros, foram pesquisados não somente in vivo ${ }^{[14,16,34]}$, mas in vitro, com os diversos tipos celulares, tais como os fibroblastos, as células de Schwann e neurônios ${ }^{[2,11,13,16,35]}$.

Ainda, alguns dos estudos realizados com o neuroblastoma em cultura celular foram feitos com carbono, poli ácido lático-co-glicólico (PLGA) e nanomateriais $^{[1,12,14,32,34,36]}$.

Portanto, a escassez de trabalhos in vitro com o neuroblastoma do tipo neuro2A e os polímeros PLLA e PCL, tornam-se indícios favoráveis a apresentação desta pesquisa, o qual estudou a adesão e a proliferação destes tipos celulares sobre os polímeros ora supracitados, através da análise quantitativa. Adicionalmente, apresentamos a análise na imunocitoquímica com caracterização da expressão de PCNA e da citoquímica com o DAPI.

Para o parâmetro quantitativo, foi feita a contagem do número de células neuro2A, cultivadas por 07 dias sobre os biomateriais e na placa de cultura (grupo controle). Este último, apresentou um número médio de $976 \pm 265,10$ marcadas com PCNA e 958 $\pm 254,75$ coradas com o DAPI. Este valor foi significativamente superior àquele obtido sobre a membrana de PCL, cuja a média foi de 55,88 $\pm 33,58$ células para a marcação para o PCNA e 51,11 $\pm 28,55$ para o DAPI e, superior ao grupo PLLA, no qual foi observada a presença de $129 \pm 40,06$ e 130,33 $\pm 54,29$, para as visualizações com PCNA e DAPI, respectivamente.

Essa diferença significativa no número de células aderentes entre os mesmos biomateriais, também foi observada em outro experimento realizado por Pierucci et al. ${ }^{[16]}$, quando foram estudados a expressão dos componentes da matriz extracelular pelas de Schwann sobre os mesmos biomateriais. Entre outros resultados apresentados pelo pesquisador, foram observados diferenças no comportamento das células neuro2A no que se diz respeito à adesão e a morfologia celular sobre as membranas de poli ${ }_{\text {L- }}$ acído láctico (PLLA) e poli caprolactona (PCL), podendo os diferentes biomateriais repercutir na taxa de adesão celular e/ou em sua proliferação.

A analise quantitativa em ensaio in vitro através da marcação com DAPI também foi empregada por Mitchell et al. ${ }^{[37]}$, os quais observaram o crescimento de neurites em cultura de neurônios granulares do cerebelo e da uma linhagem específica NG108-15.

Quanto a morfologia das células neuro2A, notou-se que estas células tinham o formato esférico quando cultivadas sobre os biomateriais, idênticas ao observado pelos pesquisadores Noguchi et al. ${ }^{[25]}$ e Liu et al. ${ }^{[26]}$, no grupo controle, diferentemente do formato bipolar e multipolar dos grupos experimentais. Ainda, Wu et al. ${ }^{[38]}$, observaram em seus experimentos que as células de glioma quando cultivadas em meio DMEM e $10 \%$ de soro fetal bovino apresentavam uma morfologia esférica, independentemente de estarem aderidas umas às outras.

Já, outros trabalhos in vitro com o neuroblastoma focaram a ação de agentes químicos na investigação de toxicidade celular, tais como o cobalto, cloridrato de cocaína $^{[39,40]}$ e metais pesados como lítio e níquel ${ }^{[41]}$. Os resultados mostraram que a ação destes causavam uma mudança morfológica nos neurônios, além de alterações fisiológicas e metabólicas, tais como vacuolização citoplasmática e degeneração nuclear ${ }^{[40,41]}$.

Como base nos resultados expressos acima, podemos observar que a técnica de solvente apresentado nesta metodologia evidencia a ausência de toxicidade celular nas membranas poliméricas, pelo fato das células apresentarem a integridade nuclear, observada pela coloração com o DAPI, bem como a presença da atividade nuclear, evidenciada pela intensa marcação com o PCNA. Não obstante, o pesquisador Atif et al. ${ }^{[42]}$, utilizou o PCNA e DAPI em seu trabalho, o qual investigou a ação da progesterona na inibição do neuroblastoma. Ainda, Hossain et al. ${ }^{[43]}$ ao estudar uma nova terapia para o tratamento de neuroblastoma, através da expressão do oncogene $\mathrm{N}$-myc utilizando ARN, agregado ao plasmídeo (shRNA) com a finalidade de aumentar a eficácia antitumoral da apigenina isoflavonoide (APG), avaliaram a morfologia celular e a apoptose nuclear através da marcação com DAPI.

Já, o tratamento do neuroblastoma in vivo e in vitro foram estudados por outros autores, tais Yasuda et al. ${ }^{[14]}$ e Häfeli et al. ${ }^{[34]}$, utilizando-se microesferas de poli ácido lático (PLA) contendo inibidores angiogênicos e com radioatividade. Os resultados apresentados foram excelentes para o tratamento tumoral e, surgiu uma nova proposta para a radioterapia.

Desta forma, ao contrário a metodologia empregada pelos autores acima, acredita-se que as membranas confeccionadas ora pela metodologia do solvente podem vir a receber medicamentos/drogas antitumorais integrada na matriz polimérica como sendo uma alternativa no tratamento de neuroblastomas.

\section{Conclusões}

A metodologia do solvente para a confecção das membranas de PCL e PLLA não resultou em toxicidade celular pelo fato de observar células aderentes e com a morfologia preservada. Quando realizado a contagem do número de células, percebe-se que o número de células aderidas na membrana de PLLA foi significantemente superior as das membranas de PCL, embora o grupo controle apresente um contingente superior aos biomateriais. Sendo assim, nota-se que houve diferenças na adesão das células neuro2A sobre as membranas de poli ${ }_{\text {L- }}$ acído láctico (PLLA) e poli caprolactona (PCL), devido a regularidade da superfície polimérica, a qual pode repercutir na taxa de adesão celular e/ou em sua proliferação. Ainda, acredita-se que as membranas possam a vir a receber medicamentos/ drogas antitumorais integrados a matriz polimérica para tratamento de neuroblastomas. 


\section{Agradecimentos}

Agradeço à FAPEMIG pelo apoio financeiro.

\section{Referências Bibliográficas}

1. Jain, S.; Sharma, A. \& Basu, B. - J. Biomed. Mater. Res. B Appl. Biomater., 101, p.520 (2013). http://dx.doi.org/10.1002/ jbm.b.32852. PMid:23359403

2. Zhao, J.; Han, W.; Tang, M.; Tu, M.; Zeng, R.; Liang, Z. \& Zhou, C. - Mater Sci Eng C Mater Biol Appl., 33, p.1546 (2013). http://dx.doi.org/10.1016/j.msec.2012.12.060. PMid:23827607

3. Brunetti, V.; Maiorano, G.; Rizzello, L.; Sorce, B.; Sabella, S.; Cingolani, R. \& Pompa, P. P. - Proc. Natl. Acad. Sci. USA., 107, p.6264 (2010). http://dx.doi.org/10.1073/ pnas.0914456107. PMid:20308580

4. Lamour, G.; Eftekhari-Bafrooei, A.; Borguet, E.; Souès, S. \& Hamraoui, A. - Biomaterials., 31, p.3762 (2010). http://dx.doi. org/10.1016/j.biomaterials.2010.01.099. PMid:20149439

5. Li, G. N.; Livi, L. L.; Gourd, C. M.; Deweerd, E. S. \& Hoffman-Kim, D. - Tissue Eng., 13, p.1035 (2007). http:// dx.doi.org/10.1089/ten.2006.0251. PMid:17439391

6. Chaturvedi, V.; Kumar, J. U.; Paithankar, K. R.; Vanathi, P. \& Sreedhar, A. S. - Med. Chem., 7, p.454 (2011). http://dx.doi. org/10.2174/157340611796799212. PMid:21801149

7. Straub, J. A.; Sholler, G. L. \& Nishi, R. - BMC Dev. Biol., 7, p.10 (2007). http://dx.doi.org/10.1186/1471-213X-7-10. PMid:17309801

8. Graciele Zanon, Z.; Pierucci, A. \& Oliveira, R. L. A. - Acta Neurobiol. Exp. (Wars)., 69, p.146 (2009). PMid:19325648.

9. Morelli, S.; Piscioneri, A.; Messina, A.; Salerno, S.; Al-Fageeh, M. B.; Drioli, E. \& Bartolo, L. D. - J. Tissue Eng. Regen. Med. [Epub ahead of print] (2012).

10. Graham, A. H.; Bowen, C. R.; Taylor, J. \& Robbins, J. Biomed. Microdevices., 11, p.1091 (2009). http://dx.doi. org/10.1007/s10544-009-9326-4. PMid:19459049

11. Corrales, T.; Larraza, I.; Catalina, F.; Portolés, T.; Ramírez-Santillán, C.; Matesanz, M. \& Abrusci, C. Biomacromolecules., 13, p.4247 (2012).PMid:23153018.

12. Doggui, S.; Sahni, J. K.; Arseneault, M.; Dao, L. \& Ramassamy, C. - J. Alzheimers Dis., 30, p.377 (2012). PMid:22426019.

13. Simşek, M.; Capkın, M.; Karakeçili, A. \& Gümüşderelioğlu, M. - J. Biomed. Mater. Res. A., 100, p.3332 (2012). http:// dx.doi.org/10.1002/jbm.a.34287. PMid:22733685

14. Yasuda, C.; Sakata, S.; Kakinoki, S.; Takeyama, Y.; Ohyanagi, H. \& Shiozaki, H. - Pathophysiology., 17, p.149 (2010). http:// dx.doi.org/10.1016/j.pathophys.2009.04.003. PMid:19540735

15. Pierucci, A.; Duek, E. A. \& de Oliveira, A. L. - J. Mater. Sci. Mater. Med., 20, p.489 (2009). http://dx.doi.org/10.1007/ s10856-008-3614-z.PMid:18987957

16. Pierucci, A.; de Duek, E. A. \& de Oliveira, A. L. - Tissue Eng. Part A., 14, p.595 (2008). http://dx.doi.org/10.1089/ tea.2007.0271. PMid:18399734

17. Rezwan, K.; Chen, Q. Z.; Blaker, J. J. \& Boccaccini, A. R. Biomaterials., 27, p.3413 (2006). http://dx.doi.org/10.1016/j. biomaterials.2006.01.039. PMid:16504284

18. Daly, W. T.; Knight, A. M.; Wang, H.; de Boer, R.; Giusti, G.; Dadsetan, M.; Spinner, R. J.; Yaszemski, M. J. \& Windebank, A. J. - Biomaterials., 34, p.8630 (2013). http://dx.doi. org/10.1016/j.biomaterials.2013.07.086. PMid:23937914

19. Haastert-Talini, K.; Geuna, S.; Dahlin, L. B.; Meyer, C.; Stenberg, L.; Freier, T.; Heimann, C.; Barwig, C.; Pinto, L. F.; Raimondo, S.; Gambarotta, G.; Samy, S. R.; Sousa,
N.; Salgado, A. J.; Ratzka, A.; Wrobel, S. \& Grothe, C. Biomaterials., 34, p.9886 (2013). http://dx.doi.org/10.1016/j. biomaterials.2013.08.074. PMid:24050875

20. Reid, A. J.; de Luca, A. C.; Faroni, A.; Downes, S.; Sun, M.; Terenghi, G. \& Kingham, P. J. - Neurosci. Lett., 544, p.125 (2013). http://dx.doi.org/10.1016/j.neulet.2013.04.001. PMid:23583695

21. Lehtonen, T. J.; Tuominen, J. U. \& Hiekkanen, E. - Acta Biomater., 9, p.4868 (2013). http://dx.doi.org/10.1016/j. actbio.2012.08.052. PMid:22963847

22. Teixeira, A. I.; Ilkhanizadeh, S.; Wigenius, J. A.; Duckworth, J. K.; Inganäs, O. \& Hermanson, O. - Biomaterials., 30, p. 4567 (2009). http://dx.doi.org/10.1016/j.biomaterials.2009.05.013. PMid:19500834

23. Zahir, T.; Nomura, H.; Guo, X. D.; Kim, H.; Tator, C.; Morshead, C. \& Shoichet, M. - Cell Transplant., 17, p.245 (2008). http://dx.doi.org/10.3727/096368908784153887. PMid:18522228

24. Wong, D. Y.; Hollister, S. J.; Krebsbach, P. H. \& Nosrat, C. - Tissue Eng., 13, p.2515 (2007). http://dx.doi.org/10.1089/ ten.2006.0440. PMid:17655492

25. Noguchi, S.; Sumida, T.; Ogawa, H.; Tada, M. \& Takahata, K. - Biosci. Biotechnol. Biochem., 67, p.2467 (2003). http:// dx.doi.org/10.1271/bbb.67.2467. PMid:14646211

26. Liu, H.; Kojima, N.; Kurosawa, N. \& Tsuji, S. - Glycobiology., 7, p.1067 (1997). http://dx.doi.org/10.1093/glycob/7.8.1067. PMid:9455907

27. Rao, V. N.; Kishore, A.; Sarkar, S.; Das Sarma, J. \& Shunmugam, R. - Biomacromolecules., 13, p.2933 (2012). http://dx.doi.org/10.1021/bm300968y. PMid:22867006

28. Yanaka, N.; Nogusa, Y.; Fujioka, Y.; Yamashita, Y. \& Kato, N. - FEBS Lett., 581, p.712 (2007). http://dx.doi.org/10.1016/j. febslet.2007.01.035. PMid:17275818

29. Oh-Hashi, K.; Hirata, Y. \& Kiuchi, K. - Cell. Mol. Biol. Lett., 18, p.398 (2013). http://dx.doi.org/10.2478/s11658-0130096-x. PMid:23864333

30. Nguyen, N. T.; Ooi, L.; Piller, S. C. \& Münch, G. - Mol. Nutr. Food Res., [Epub ahead of print] (2013).

31. Nicoli Aldini, N. N.; Perego, G.; Cella, G. D.; Maltarello, M. C.; Fini, M.; Rocca, M. \& Giardino, R. - Biomaterials., 17, p.959 (1996). http://dx.doi.org/10.1016/0142-9612(96)846692. PMid: 8736729

32. Ciofani, G.; Danti, S.; D’Alessandro, D.; Moscato, S. \& Menciassi, A. - Biochem. Biophys. Res. Commun., 394, p.405 (2010). http://dx.doi.org/10.1016/j.bbrc.2010.03.035. PMid:20226164

33. Pulieri, E.; Chiono, V.; Ciardelli, G.; Vozzi, G.; Ahluwalia, A.; Domenici, C.; Vozzi, F. \& Giusti, P. - J. Biomed. Mater. Res. A., 86, p.311 (2008). http://dx.doi.org/10.1002/jbm.a.31492. PMid: 17969018

34. Häfeli, U. O.; Sweeney, S. M.; Beresford, B. A.; Humm, J. L. \& Macklis, R. M. - Nucl. Med. Biol., 22, p.147 (1995). http:// dx.doi.org/10.1016/0969-8051(94)00124-3. PMid:7767307

35. Lai, Y.; Cheng, K. \& Kisaalita, W. - PLoS ONE., 7, p.e45074 (2012). PMid:23049767.

36. Kelly, S.; Regan, E. M.; Uney, J. B.; Dick, A. D.; McGeehan, J. P.; Bristol Biochip Group; Mayer, E. J. \& Claeyssens, F. Biomaterials., 29, p.2573 (2008). http://dx.doi.org/10.1016/j. biomaterials.2008.03.001. PMid:18359076

37. Mitchell, P. J.; Hanson, J. C.; Quets-Nguyen, A. T.; Bergeron, M. \& Smith, R. C. - J. Neurosci. Methods., 164, p.350 (2007). http://dx.doi.org/10.1016/j.jneumeth.2007.04.021. PMid: 17570533

38. Wu, A.; Pangalos, M. N.; Efthimiopoulos, S.; Shioi, J. \& Robakis, N. K. - J. Neuroscience., 17, p.4987 (1997). 
39. Repetto, G.; Sanz, P. \& Repetto, M. - Toxicol. In Vitro., 9, p.375 (1995). http://dx.doi.org/10.1016/0887-2333(95)000287. PMid:20650102

40. Repetto, G.; Del Peso, A.; Garfia, A.; Gonzalez-Muñoz, M. J.; Salguero, M.; Sanz, P. \& Repetto, M. - Toxicol. In Vitro., 11, p.519 (1997). http://dx.doi.org/10.1016/S08872333(97)00066-0. PMid:20654345

41. Repetto, G.; del Peso, A.; Sanz, P. \& Repetto, M. - Toxicol. In Vitro., 15, p.363 (2001). http://dx.doi.org/10.1016/S08872333(01)00037-6. PMid:11566564
42. Atif, F.; Sayeed, I.; Yousuf, S.; Ishrat, T.; Hua, F.; Wang, J.; Brat, D. J. \& Stein, D. G. - Molmed., 17, p.1084 (2011).

43. Hossain, M. M.; Banik, N. L. \& Ray, S. K. - Gene., 529, p.27 (2013). http://dx.doi.org/10.1016/j.gene.2013.07.094. PMid:23941992

Enviado: Out. 25, 2013 Reenviado: Jun. 04, 2014 Aceito: Jun. 09, 2014 